\title{
Awareness and knowledge of human papilloma virus (HPV) vaccine in prevention of cervical cancer among medical students
}

\author{
Radhika M., Sadiqunissa*, Mehfooza Ahmed
}

Department of Obstetrics and Gynecology, Yenepoya Medical College and Hospital, Mangalore, Karnataka, India

Received: 27 September 2018

Accepted: 22 October 2018

\section{*Correspondence:}

Dr. Sadiqunissa,

E-mail: sadiqamukhtar64@gmail.com

Copyright: (C) the author(s), publisher and licensee Medip Academy. This is an open-access article distributed under the terms of the Creative Commons Attribution Non-Commercial License, which permits unrestricted non-commercial use, distribution, and reproduction in any medium, provided the original work is properly cited.

\begin{abstract}
Background: Cervical cancer is the most common malignancy amongst women in India. Identification and prevention of the pre-cancerous lesions helps to reduce the incidence of Carcinoma of cervix. The main aim of the study is to know the awareness and knowledge of HPV vaccine in prevention of cervical cancer among medical students.

Methods: The study included 97 medical students (final year) studying in Yenepoya Medical College, Mangalore. It is a cross-sectional questionnaire-based study.

Results: The results of awareness and knowledge about the HPV vaccine are interpreted in percentage. In this study, $76 \%$ of study subjects were aware that cancer cervix is preventable, $80 \%$ of the study subjects were aware about the association between the causation of cancer cervix by HPV. Majority of the study subjects about $72 \%$ ware about the vaccines for HPV but, awareness about the cost and efficacy of the vaccine was low only about 30\% and 10\% respectively. However, importantly students had a positive attitude to educate people regarding HPV vaccination and also to clear myths and misconceptions.

Conclusions: Medical students should be educated regarding HPV infection, risk factors for causation of cervical cancer, screening methods which are available, HPV vaccines available in India and also about the efficacy and to motivate the society to have a positive attitude towards HPV vaccination by clearing the misconceptions regarding its information.
\end{abstract}

Keywords: HPV-human papilloma virus, Prevention, Vaccine

\section{INTRODUCTION}

Cervical cancer common worldwide and its ranks third among all the malignancies in women. ${ }^{1}$ Globally, cervical cancer is the second most common cancer among women. Every year 5,00,000 new cases diagnosed and about $2,70,000$ die every year $85 \%$ in developing countries. $^{2}$

The age at which cervical cancer developes is in general earlier than other gynecological malignancies and median age at diagnosis is about 48 years. ${ }^{3}$ Cervical cancer incidence rates remains high in Central and South
America, eastern Africa, South and South-East Asia, and Melanesia. India alone represents one-fifth of the world's cervical cancer burden. ${ }^{4}$

Genital human papillomavirus (HPV), the most common sexually transmitted virus, as the cause of cervical cancer. Most HPV infections are cleared naturally by body's immune system, persistent infection manifest into cervical cancer. Approximately, 10-20 years for a precursor lesion caused by HPV to develop into cervical cancer, screening and early detection are essential in preventing deaths. ${ }^{5}$ There are more than 140 HPV types but only about 40 sexually transmitted virus. Two high 
risk HPV types 16 and 18 responsible for more than $80 \%$ of cervical cancers in India. ${ }^{6}$

Risk factors such as early age of marriage, multiple sexual partners, multiple pregnancies, poor genital hygiene and smoking in development of cervical cancer. ${ }^{7}$ The USFDA approved and commercially available vaccines for HPV in India, Gardasil which is quadrivalent (HPV 16, 18, 6, 11), Cervarix which is bivalent (HPV 16, 18) among adolescent girls ages 9-13 years and young adults age 13-26 years. ${ }^{8}$ Nonvalent vaccine is similar to quadrivalent vaccine and it contains virus like particles for HPV types 6, 11, 16, 18, 31, 33, 45, 52 and 58 with increased amount for types 16,18 and $6 .{ }^{9}$ In 2014 WHO recommended 2 doses 6-12 months apart for those aged 14 years and under at first dose. But those who are $>15$ years and immunocompromised still require 3 doses 0,2 and 6 months. ${ }^{10}$

In men, about $92 \%$ of anal cancer, $63 \%$ of penile cancers and $89 \%$ of oral or oropharyngeal cancers are due to HPV types 16 and 18 . Hence Quadrivalent vaccine is approved and recommended for both sexes. ${ }^{11}$ Individuals can reduce their risk of an HPV infection by engaging in safer sexual behaviours (eg, condom use, delaying onset of sexual activity, having sex with a monogamous partner). Papanicolaou (Pap) smear screenings (the most common cervical cancer screening test) is important in detecting early cellular changes including pre-cancerous cells. ${ }^{12}$

Inspite of USFDA recommendations of HPV vaccines, which is highly immunogenic, safe, well tolerated and highly effective in prevention of HPV infection, but still it is not a part of National Immunization Programme because of certain unrelated deaths occurred during HPV vaccine immogenecity trials conducted in Andhra Pradesh and Gujurath by PATH and ICMR. ${ }^{13}$ And also high cost of vaccine and vaccine delivery, low cervical screening levels, inaccessibility to medical care, low awareness and knowledge of HPV and cervical cancer. ${ }^{14}$ Western countries like USA and Europe HPV vaccines included in national immunization programme for reducing burden of cervical cancer. ${ }^{15}$

In addition, social, cultural, religious and ethical issues can create difficulties when administering a vaccine that prevents a sexually transmitted infection to young women. Efforts directed towards decreasing the morbidity and mortality associated with cervical cancer requires both health providers and patients to practice preventive measures such as Pap smear screenings and HPV vaccination when available. The Health care professionals play a role in creating awareness and promoting cervical cancer screening among women in their field practice area. Their attitudes are often crucial in gaining women's confidence. It is therefore, relevant to appraise the perception and utilization of cervical cancer screening services by health care professionals. ${ }^{16}$ Lack of knowledge about the cancer in the population and among healthcare workers is a prime barrier for access to cervical cancer prevention. The purpose of this study was to examine the knowledge and behaviours of undergraduate health science students associated with HPV, cervical cancer screening and HPV vaccine.Medical students are chosen because they are the first line resource of information in clearing myths and spreading awareness regarding cervical cancer. Hence it helps in promoting vaccine acceptance and positively influence screening for cervical cancer.

\section{METHODS}

A Cross-sectional questionnaire-based study carried out among medical students (final year) in Yenepoya Medical College and Hospital, Mangalore in June 2017July 2017.

The medical students of final year MBBS, who were present on that day were taken as study participants. The study was limited to one day. The students who were absent on that particular day, first, second and third year MBBS students and also who were not willing to participate were excluded from the study. The medical students were explained about the purpose of the study and its usefulness in preventing carcinoma of cervix and then informed oral and written consent obtained. All participants were informed that their responses would remain confidential.

A self-administered questionnaire, with closed and a few open-ended questions. The questionnaire contains 19 multiple choice questions covering the topics of knowledge of HPV, cervical cancer, HPV vaccines and also knowledge about cervical cancer and risk factors, primary prevention, secondary prevention and HPV vaccines and also their attitude towards the screening procedures and acceptance of the HPV vaccines. The data obtained were analysed with descriptive statistics, frequencies and percentages were calculated for each item in the questionnaire.

Sample size: 97

\section{Formula}

$\mathrm{n}=[(\mathrm{z})]^{\wedge} 2 \mathrm{pq} /[(\mathrm{d})]^{\wedge} 2$

$\mathrm{z}=$ standard normal deviant at $95 \%$ confidence level that is 1.96

$\mathrm{p}=$ prevalence of knowledge $50 \%$

$\mathrm{d}=$ relative precision of $20 \%$

$\mathrm{n}=(1.96) 2 * 50 * 50 /(10) 2$

$\mathrm{n}=96.04$.

\section{RESULTS}

A total of 97 medical students participated in the study. Out of which, 40 girls and 57 boys in age group of 22-25 years. About, $78.35 \%$ of the students were aware that the cervical cancer is preventable, $21.64 \%$ of students not aware that it is a preventable disease. $82.47 \%$ of students knew that the cervical cancer is caused by the virus, 
$17.52 \%$ of students were not aware of the viral etiology. About, $74.22 \%$ of students aware that the vaccine is available for prevention of Cervical cancer and $60.82 \%$ of students knew that vaccines available in India, however they did not know the names of the vaccines available commercially (Table 1).

Table 1: Awareness about the HPV vaccines.

\begin{tabular}{|llll|}
\hline Questions & Correct (yes) & Incorrect (no) & Don't know \\
\hline Cervical cancer is preventable & $76(78.35 \%)$ & $21(21.64 \%)$ & - \\
\hline Cervical cancer caused by virus & $80(82.47 \%)$ & $17(17.52 \%)$ & - \\
\hline Is there vaccine available for cervical cancer & $72(74.22 \%)$ & $10(10.30 \%)$ & $15(15.46 \%)$ \\
\hline HPV vaccine is given in which age group & $75(77.31)$ & $22(22.68 \%)$ & - \\
\hline Commercially available vaccines in India & $55(56.70 \%)$ & $34(35.05 \%)$ & $8(8.24 \%)$ \\
\hline Cost of HPV vaccine & $30(30.92 \%)$ & - & $67(69.07 \%)$ \\
\hline Do you like to advice or receive HPV vaccines & $94(96.90 \%)$ & $3(3.09 \%)$ & - \\
\hline Has anybody sought your opinion regarding HPV vaccination & $67(69.07 \%)$ & $30(30.92 \%)$ & - \\
\hline
\end{tabular}

Table 2: Knowledge about the HPV vaccine.

\begin{tabular}{|llll|}
\hline Questions & Correct (yes) & Incorrect (no) & Don't know \\
\hline Can it be given to boys & $45(46.39 \%)$ & $12(12.37 \%)$ & $40(41.23 \%)$ \\
\hline Can it be given to sexually active girls & $84(86.59 \%)$ & $13(13.40 \%)$ & - \\
\hline Is there is a need to be screened for HPV before getting vaccinated & $30(30.92 \%)$ & $49(50.51 \%)$ & $18(18.55 \%)$ \\
\hline Can it be given to woman already having HPV infection & $46(47.42 \%)$ & $31(31.95 \%)$ & $20(20.61 \%)$ \\
\hline How many doses of HPV vaccine required for protection & $74(76.28 \%)$ & $36(37.11 \%)$ & $13(13.40 \%)$ \\
\hline Route of administration of HPV vaccine & $84(84.59 \%)$ & $13(13.40 \%)$ & - \\
\hline Interval between the doses & $63(64.94 \%)$ & $18(18.55 \%)$ & $16(16.49 \%)$ \\
\hline Do girls require screening after getting vaccinated & $60(61.85 \%)$ & $37(38.14 \%)$ & - \\
\hline Cervical cancer protection by vaccines & $10(10.30 \%)$ & $60(61.85 \%)$ & $27(27.83 \%)$ \\
\hline
\end{tabular}

About, $77.31 \%$ of students had the knowledge about the HPV vaccines, regarding recommended age group of 912 years. Majority of the students about $41.23 \%$ did not know whether the boys can be vaccinated for HPV infections and about $30.92 \%$ of students said that screening has to be done before getting vaccinated (Table 2 ). The knowledge regarding the role of vaccination in a woman who has been already infected with HPV infection was low among the medical students and about only $31.95 \%$ of students knew that vaccination has no role in women with HPV infection. More interestingly, $76.28 \%$ has knowledge regarding the dosage schedule as 3 doses and $84.59 \%$ knew the route of administration of vaccine as IM, $64.94 \%$ were aware of the interval between the 3 doses as 0, 2 and 6 months (Table 2). Majority of the students $35.05 \%$, were unaware about the availability of vaccines in India and about the newer vaccines and major drawback about the awareness regarding HPV vaccination efficacy i.e., $40 \%$ of students did not have adequate information and about the $10 \%$ of students were not aware of the cost and $30 \%$ of students not compliant enough due to misconception regarding the complications and not the least $20 \%$ dint have adequate information (Table 1). The important aspect of this study is that $69.07 \%$ of students gave a positive response to advice or receive HPV vaccination to prevent cervical cancer. Majority of the people have sought their opinion regarding the vaccination. Hence, medical students have an important role in educating people regarding the HPV vaccines available and to counsel them in order to prevent the burden of cervical cancer in India (Table 1).

\section{DISCUSSION}

Cervical cancer is a major cancer in India and it is preventable cancer, if detected early. The two major highrisk oncogenic HPV genotypes, HPV 16 AND 18 most commonly associated, highly prevalent in India. The development of HPV vaccine represents a huge advancement in preventing cancer of cervix but the awareness about the vaccination is still very low and has many myths and misconceptions. The study aims at the awareness and attitude of our medical students (final year) towards HPV infection and vaccine for preventing cancer cervix. We observed that $55 \%$ of students unaware about the commercial vaccines available in India and its cost and efficacy, but whereas study conducted in Belgium among women attending the routine gynecological care showed only $50 \%$ of them aware about the vaccine's availability. ${ }^{17}$ In Ghanain study conducted among the women where majority of them had received higher education, only $40 \%$ had heard about HPV vaccine, but our study showed that $72 \%$ of medical students aware about the HPV vaccine. ${ }^{18}$ But study 
revealed that most of the students were having a positive attitude towards the vaccination to receive or advice to the public and medical students plays a role in providing information to society regarding cervical cancer, its risk factors and using HPV vaccine to reduce the incidence of cervical cancer. The major obstacles to the implementation of the HPV vaccine programmes in our country as mentioned by the Bhatla $\mathrm{N}$ et al included cost, acceptability, lack of public awareness and infrastructure, concern about the side effects and social and religious barriers. $^{19}$

This kind of interactive session and informative session helps the receptive minds to have a positive attitude following interrogative session. But this study has some limitations, because this study based on convenient sampling. Medical students from only one medical school were included which might not reflect the overall awareness of medical students in India. Inclusions of other health workers need to be educated about how to help patients to understand prevention strategy for cervical cancer. None of the students showed unwillingness to participate in the study. Ojiyi et al, HPV vaccine awareness was high $74 \%$ and most of the health workers $67.3 \%$ would recommend the vaccines to their adolescent daughters and clients. Similarly, even S Mehta et al reported that $66.8 \%$ willing to accept the HPV vaccines. ${ }^{20}$ Similarly, Pandey et al studied awareness and attitude about the HPV vaccines among medical students in India, found that the majority of the participants were well aware of the preventable nature of the cervical cancer. $^{21}$

Mc Carey et al in 2011 studied awareness of HPV and cancer cervix prevention among Cameroonian health care workers and found several gaps regarding screening methods hence, creating awareness among health care workers on risk factors and current methods to screen and prevent cervical cancer should be implemented for effective cervical cancer preventing programs. ${ }^{14}$ Durosoy, et al, on HPV vaccine awareness and its willingness among first year medical students entering university in western Turkey revealed that the knowledge amongst them was poor and only $11.6 \%$ females intended to get vaccinated vs $94 \%$ in our study. ${ }^{22}$ A higher proportion of incorrect answers were reported about the protection rate of carcinoma cervix by the HPV vaccine, about $60 \%$ and also had low knowledge regarding HPV vaccination in boys. Hence, there is an imperative need for educational intervention and also educating them regarding successful implementation of screening and vaccination programmes in order to reduce the incidence of carcinoma cervix.

\section{CONCLUSION}

HPV vaccine for primary prevention of cervical cancer and it can be practiced only if it is clearly understood and having the knowledge about the HPV vaccines and also attitude to accept it. Health care professionals play a role in providing information regarding its efficacy and need for preventing cervical cancer. And medical schools need to be focused as an academic curriculum on such priority practical upcoming advancement as they are source of information to the society and educating them. Study suggests that medical students should be educated regarding HPV infection, risk factors for causation of cervical cancer, screening methods available, HPV vaccines available in India and also about its efficacy and to motivate society to have a positive attitude towards HPV vaccination by clearing the misconceptions regarding its information.

\section{ACKNOWLEDGMENTS}

Authors would like to thank Dr. Sadiquinnis, Dr. Mehfooza Ahmed and to Medical students of Yenepoya Medical College and Hospital for their support during study.

Funding: No funding sources

Conflict of interest: None declared

Ethical approval: The study was approved by the Institutional Ethics Committee

\section{REFERENCES}

1. Ferlay J, Shin HR, Bray F, Forman D, Mathers C, Parkin DM: Estimates of worldwide burden of cancer in 2008: GLOBACON 2008. Int J Cancer 2010;127(12):2893-917.

2. WHO/ICO Information Center on HPV and Cervical Cancer. HPV and cervical cancer in the 2007 report. Vaccine 2007;25(3):C1-C230.

3. National Cancer Institute: Surveillance Epidemiology and End Results. 2011.

4. Lalikangbam $P$, Sengupta S, Bhattacharya $P$, Duttagupta C, Dhabali Singh T, Verma Y et al. A comparative profile of the prevalence and age distribution of human papillomavirus type 16/18 infections among three states of india with focus on northeast India. Int J Gynecol Cancer. 2007;17(1) 107-17.

5. Kay Perrin, Rajal Thaker, Ellen Daley, Cheryl Vamos, Pankaj Patel HPV knowledge and behavioral intention among health science undergraduate students: Influence of future health care professionals NHL J Med Sci. 2013;(2)15-21.

6. Lowy DR, Schiller JT. Reducing HPV-associated cancer globally. Cancer Prev Res (Phila).2012;5(1):18-23.

7. Das BC, Gopalkrishna V, Hedau S K S. Cancer of the Uterine Cervix and Human Papilloma Viruses. Curr Sci. 2000;78(1);52-63.

8. Markowitz LE, Dunne EF, Saraiya M, Lawson HW, Chesson H, Unger ER, et al. Quadrivalent Human Papilloma virus. Recommendation of the Advisory comitte on Immunization Practices.2007;56:1-24.

9. Brotherton JM. Human papillomavirus vaccination update: Nonavalent vaccine and the two-dose 
schedule. Australian journal of general practice. 2018;47(7):417.

10. D'Addario M, Redmond S, Scott P, Egli-Gany D, Riveros-Balta AX, Restrepo AM et al. Two dose schedule for human papilloma virus vaccine; Systematic review and meta-analysis. Vaccine 2017;35(22):2892-901.

11. Canadian Immunization Committee. Summary of Canadian Immunization Committee (CIC) recommendations for human papilloma virus immunization programs. Can Commun Dis Rep. 2014;40(8):152-3.

12. Anantharaman VV, Sudharshini S, Chitra A. A cross-sectional study on knowledge, attitude, and practice on cervical cancer and screening among female health care providers of Chennai corporation, 2013. J Acad Med Sci. 2012;2(4):124.

13. Choudhury P, John TJ. Human papilloma virus vaccines and current controversy. Indian Pediatr.2010;47(8):724-5.

14. Rathod S, Samal SK, Samal S, Ghose S. knowledge and awareness of cervical cancer and Human Papilloma Virus Vaccine among Medical Students: A Cross-sectional Study. J South Asian Feder Menopause Soc. 2017;5(1):41-44.

15. Rashid S, Labani S, Das BC. Knowledge, awareness and attitude on HPV, HPV vaccine and cervical cancer among the college students in India. PloS one. 2016;11(11):e0166713.

16. McCarey C, Pirek D, Tebeu PM, Boulvain M, Doh AS, Petignat P. Awareness of HPV and cervical cancer prevention among Cameroonian healthcare workers. BMC women's health. 2011;11(1):45.

17. Donders GG, Gabrovska M, Bellen G, Van Keirsbilck J, Van Den Bosch T, Riphagen I, et al
Knowledge of cervix cancer, human papilloma virus (HPV) and HPV vaccination at the moment of introduction of the vaccine in women in Belgium. Arch Gynecol Obstet. 2008;277(4):291-8.

18. Coleman MA, Levison J, Sanji-Hanghpeyakar H. HPV vaccine acceptability in Ghana, West Africa. Vaccine 2011;29(23):3945-50.

19. Bhatla N, Joseph E. Cervical cancer prevention \& the role of human papillomavirus vaccines in India. Indian J Med Res. 2009;130(3):334.

20. Ojiyi CE, Dike EI, Okeudo C, Nzewuihe AC, Uzoma MJK. Human papilloma virus vaccine: awareness and acceptability amongst female medical students and health workers in a University Teaching Hospital in Eastern Nigeria. Niger J Surg Sci 2013;23(1):1417.

21. Pandey D, Vanya V, Bhagat S, Binu VS, Shetty J. Awareness and attitude towards human papilloma virus (HPV)vaccine among medical students in a Premier Medical School in India.PLos One 2012;7(7);e40619.

22. Durosoy R, Yamazhan M, Taskbakan MI, Ergin I, Aysin M, Pullukcu H, et al. HPV vaccine awareness and willingness of first-year students entering university in western Turkey. Asian Pac J Cancer Prev. 2010;11(6):1695-701.

Cite this article as: Radhika M, Sadiqunissa, Ahmed M. Awareness and knowledge of human papilloma virus (HPV) vaccine in prevention of cervical cancer among medical students. Int J Reprod Contracept Obstet Gynecol 2018;7:5026-30. 